\title{
El maltrato y la violencia estrechan y aniquilan lo psíquico*
}

Abuse and Violence Narrow and Annihilate the Psychic

Recibido: abril 23 de 2013 | Revisado: marzo 14 de 2014 | Aceptado: marzo 14 de 2014

\author{
Cecilia Muñoz Vila ** \\ Nubia Esperanza TORRES CALDERÓN*** \\ Pontificia Universidad Javeriana, Colombia
}

doi:10.11144/Javeriana.UPSY13-3.mvea

Para citar este artículo: Muñoz, C., \& Torres, N. E. (2014). El maltrato y la violencia estrechan y aniquilan lo psíquico. Universitas Psychologica, 13(3), 1099-1110. http://dx.doi.org/10.11144/Javeriana. UPSY13-3.mvea

\footnotetext{
Resultados conceptuales de investigación en clínica psicoanalítica.

** Profesora Maestría en Psicología Clínica. Correo electrónico:cmvila@etb.net.co

**** Correo electrónico: torresn@javeriana.edu.co
}

\begin{abstract}
RES UMEN
Se presentan los hallazgos conceptuales de un trabajo de investigaciónintervención psicoanalítico elaborado a partir del acercamiento psicoterapéutico a mujeres maltratadas cuyo material en sesión fue categorizado y analizado bajo el esquema de "revisión meditativa" de Bion. Los autores encuentran un estrechamiento psíquico como resultado de experiencias continuadas de violencia y maltrato, entendida esta como la reducción de la profundidad psíquica, hacia adentro y hacia afuera, producto de la primacía del ello y los objetos sobre el yo, de la carencia de mundo interno que lleva a acciones-reacciones motrices sin pensamiento (unidimensionalidad), del predominio de lo perceptual sensorial en la relación con el mundo externo (bidimensionalidad) y del uso alternante y permanente de supuestos básicos, todo lo cual conduce a una vida deshumanizada. Se recurre a desarrollos conceptuales que siguen la línea de Freud, Klein, Bion Meltzer y Green. Palabras clave

mujer; pareja; maltrato; estrechez psíquica; supuestos básicos; unidimensionalidad; bidimensionalidad; deshumanización

\section{A B S T R A C T}

The authors present the findings of a research on psychoanalytical therapeutic interventions with Battered women, using the "Meditative Review" proposed by Bion, categorizing and analyzing the clinical material. Continuing experiences of abuse and violence produce narrowing and annihilation of psychic, is described, by the authors, as a reduction of psychic depth, inside and outside, produced by the primacy of the id and the objects on ego instance, the absence of the internal world leading to motor actionreactions, without thought (one-dimensionality), with sensory perception predominance (two-dimensionality) and alternating permanent use of Basic Assumptions leading to dehumanized life. The analytical conceptual framework used follows the Freud, Klein, Bion, Meltzer and Green research lines.

Keywords

woman; couple; abuse; mental narrowness; Basic Assumptions; one-dimensionality; tow-dimensionality; dehumanization
\end{abstract}


Durante tres años consecutivos, dos profesoras de un programa de Maestría de Psicología Clínica con énfasis en psicoterapia psicoanalítica, junto con estudiantes que efectuaban trabajos de grado, concentraron sus esfuerzos en realizar procesos de investigación-intervención sobre la condición psíquica de mujeres maltratadas que se escondían junto con sus hijos en un refugio de protección, sobre niños que habían sido objeto de abandono, maltrato y abuso sexual y se encontraban bajo medidas de protección, además de atender pacientes hombres y mujeres que solicitaban consulta psicológica en instituciones destinadas para esta función. Este trabajo permitió tener un acercamiento a lo que significa estar inmerso en experiencias de violencia con quienes se cohabita, y poder así analizarlas y documentarlas. La labor de investigación-intervención fue llevada a cabo bajo esquemas psicoterapéuticos de orientación psicoanalítica de carácter individual, enmarcados en los cánones académicos de formación de la Maestría.

Las categorías de análisis utilizadas surgieron de los conceptos psicoanalíticos propuestos por Freud, Klein, Bion, Meltzer, Green y algunas revisiones teóricas de algunos conceptos de estos psicoanalistas elaboradas por los autores. Elementos conceptuales centrales fueron el análisis de funcionamiento metapsicológico presente en los casos, el análisis del funcionamiento de Supuestos Básicos y la desestructuración del deseo.

\section{Aspectos metodológicos}

Las personas del estudio fueron en su mayoría habitantes de un refugio creado para proteger a mujeres y sus hijos, en riesgo de muerte, donde recibieron atención psicoterapéutica por parte de estudiantes, junto con las profesoras, que utilizaron este material fenomenológico, para la elaboración de los siguientes trabajos de grado: Rincón (2011), Amaya (2012), Gil (2010), Olarte (2012), Sanguino (2011), Caro (2012) y Zacipa (2010).

Las sesiones de trabajo fueron registradas en protocolos que sirvieron como unidades de análisis de cada uno de los procesos llevados a cabo, con el cuidado de preservar la identidad de los parti- cipantes. Este material fue codificado, separando los registros de las intervenciones del paciente, los del terapeuta y los de la relación entre los dos. El material así organizado fue sometido a la revisión de un grupo de trabajo, conformado por las dos investigadoras, un psicólogo de la institución y los estudiantes voluntarios con quienes se realizó un segundo nivel de análisis. Finalmente, las profesoras realizaron un trabajo de comprensión transversal.

Para los análisis se utilizó la técnica propuesta por Bion (1962/2008) llamada revisión meditativa, que permite ir evaluando los usos y evolución del pensar y los pensamientos de los participantes, así como la generación de hipótesis comprensivas que se consolidan o se descartan durante el proceso. De esta manera, las inferencias realizadas se sustentaron en los contenidos verbales y no verbales registrados en los protocolos, en la experiencia emocional compartida entre el paciente y el terapeuta y en el entrecruce crítico, con conceptos de funcionamiento psíquico provenientes de la serie teórica psicoanalítica. Los análisis consecutivos fueron mostrando convergencias importantes de funcionamiento que apoyaron la idea que sobre la violencia se tiene, como realidad personal perturbada y como tragedia social. En lo que sigue, haremos una presentación sucinta de nuestros hallazgos.

\section{Hallazgos conceptuales}

No es una tarea fácil presentar brevemente los resultados conceptuales de la investigación de tres años sobre el maltrato. En lo que sigue, queremos hacer énfasis en el hallazgo tal vez más impactante, la estrechez del psiquismo y la primacía de lo no psíquico en el funcionamiento de los 35 casos de personas involucradas en relaciones de maltrato, con quienes se tuvieron experiencias terapéuticas que iban entre 8 y 30 sesiones de trabajo. Tampoco fue fácil para nosotros enfrentarnos, al lado de los estudiantes, a un material de narraciones repetitivas de encuentros violentos de golpes, ataques con múltiples armas, insultos, gritos, escapadas y retornos sin fin a relaciones maltratadoras. Lo que allí observábamos ponía en entredicho todo lo que sabíamos sobre el psiquismo, su existencia, su desarrollo y 
crecimiento. Era difícil aceptar que estábamos ante un material donde no encontrábamos otra cosa que eventos concretos de realidad externa, sin que hubiera indicios de búsqueda de sentidos, significados o simbolizaciones en los recuerdos o narraciones de vida cotidiana que entregaban durante las sesiones de psicoterapia.

La mayoría de las mujeres, con una vida miserable desde la infancia, fueron sometidas a malos tratos ejercidos desde la tiranía paterna que comenzaba algunas veces con el abuso incestuoso, teñido de preferencia en la escogencia de la víctima, pero que también implicaba golpes y abandono, acompañados en muchas ocasiones por la tiranía materna, agresiva y lejana que sofocaba y forzaba al sometimiento. Con la ilusión de una nueva vida, al encontrarse con un nuevo hombre que les ofrecía amor y dedicación, se iban con él, quien, en un corto tiempo, pasaba igualmente a ejercer la misma tiranía del abuso y el maltrato, pero que, al igual que el padre, ofrecía algunos beneficios que ellas mismas estaban dispuestas a recibir. Poco a poco, entendíamos que nos movíamos hacia el terreno de la vida en lo sensorial y de actos sin pensamientos, sin que encontráramos rastros de imágenes o expresiones verbales que nos permitieran imaginar la existencia de una realidad interna en la psiquis de las mujeres maltratadas, ni en lo que ellas nos mostraban sobre los hombres con quienes había tenido, por mucho tiempo, relaciones maltratadoras. Aquellos conceptos como realidad psíquica, mundo interno, objetos internos descritos por Klein (1946/2001, 1959/2001, 1961/2001) o representaciones y pensamientos originados en la ausencia tolerada del objeto señalados por Freud (1938/1980) no se veían por ningún lado. Nos enfrentábamos a encuentros y desencuentros, huidas y regresos hacia los hombres concretos con los cuales se repetían las mismas escenas, una y otra vez, sin cambio diferente al incremento de la violencia y la inútil esperanza de un cambio que nunca se daba.

Las primeras escenas descubiertas nos llevaron a pensar en un funcionamiento no mental en el terreno de los supuestos básicos de (Bion, 1964/1980) con comportamientos socio-animales, donde no estaba presente el psiquismo, entendido como mundo interno, habitado por objetos internos proveedores de funciones de acompañamiento y protección, pero también de freno y límite sobre las demandas y reacciones infantiles, voraces, engañosas y destructivas. Tampoco aparecían imágenes alegóricas o metafóricas, ni símbolos generados en el maravilloso mundo del significado en espacios potenciales. Allí predominaban condiciones y formas de vida deshumanizantes bajo de un esquema de supervivencia, sin tener en cuenta a los otros. El siguiente hallazgo fue el de la primacía del funcionamiento regido por el ello y los objetos (Freud, 1925/1981; 1938/1981), con la casi desaparición del yo, hasta llegar así a contactar un funcionamiento no psíquico bajo la condición de vida que se daba en el espacio unidimensional y bidimensional (Meltzer, 1975/1979) donde las cualidades y las relaciones entre el self y los objetos eran diferentes a las que permitían el desarrollo del psiquismo, solo presente en el mundo interior construido con la presencia de objetos con capacidad de contención, rêverie y pensamiento (Bion, 1967/1996).

Tener que aceptar la ausencia del inconsciente y del mundo interno, claramente definidos como los descubrimiento más importantes del siglo pasado en el terreno terapéutico, nos fue muy difícil. Tuvimos que enfrentarnos a esta nueva realidad con algunas de las herramientas conceptuales que podíamos recoger de la corriente de pensamiento psicoanalítico de Freud, Klein, Bion y Meltzer. La ausencia de lo inconsciente, como la otra escena del funcionamiento psíquico, hizo que fuera necesario también pensar el lugar de su contraparte, la consciencia. La función de conciencia, como capacidad de percepción de las cualidades psíquicas no estaba presente, como tampoco lo estaba la función de "sentido común" (Bion, 1962/2008), que es lo que da lugar a la atención y correlación entre las distintas informaciones que provienen de los órganos de los sentidos y finalmente a la conciencia. En su lugar, opera la percepción de estímulos que no se encadenan entre sí, que no hacen historia y, por supuesto, tampoco adquieren sentido y significado. La vida se convierte en tomar nota de las intensidades perceptuales del afuera para protegerse o huir cuando el peligro 
aparece, o acercarse cuando lo atractivo surge en el campo perceptual.

De las escenas que reconstruíamos a partir del material de sesión surgían mujeres y hombres que se movían en el ejercicio vital dominados por demandas primitivas del ello que regía el funcionar sobre su precario desarrollo yoico. Primaba el funcionamiento del aparato perceptual y de la motricidad instrumental que les permitía moverse en el mundo y obtener de él todo aquello que pudiera satisfacer sus impulsos eróticos o destructivos, siempre bajo un esquema de acción-reacción tan simple como el movimiento de los protozoarios de agua dulce o de animales enredados en un contacto violento de guerra para sobrevivir.

Surgían también las mujeres que se adherían de manera persistente a los otros y, como estampillas pegadas en una fusión, les permitía existir a través de la imitación sencilla de las cualidades sensoriales de los otros, independientemente de su cualidad benévola o destructiva. Fue así como entendimos la posibilidad de que el impacto, de “(...) usurpación por parte del Superyó de la posición que debería ocupar el Yo implica un desarrollo deficiente del principio de realidad, la exaltación del juicio moral y la falta de respeto por la verdad. El resultado es la inanición de la psique y la quiebra del desarrollo", tal y como lo planteara Bion en su libro Transformaciones (1991/2001, p. 64). En esta condición, adherirse al objeto y a su juicio moral se convierte claramente en una estrategia de sobrevivencia.

Por otra parte, Bion en Cogitaciones (1992/1996) se refiere además a pacientes "capaces de percibir las cualidades psíquicas" de estar ansiosos, o asustados, o deprimidos", pero no pueden aprender de la experiencia, por su incapacidad de "hacer inconscientes las emociones (p. 241)", pero también por la imposibilidad de hacerlas conscientes.

El descubrimiento anterior nos llevó a explorar en las mujeres maltratadas su persistencia de compulsión a la repetición, de oscilación recurrente entre los supuestos básicos de dependencia -lucha y fuga-apareamiento, de formas de supervivencia miserables, llenas de violencia y destrucción en un ambiente deshumanizado. Esto corresponde a una visión inalterable de la existencia unidimensional primitiva de acción-reacción y atracción-repulsión o de la existencia bidimensional de cercanía irrenunciable, que no tiene en cuenta ni puede diferenciar claramente la cualidad benévola o maligna de quien tiene a su lado.

Los supuestos básicos, la deshumanización generada por la primacía del ello, y la existencia unidimensional o bidimensional creaban en ellas una constelación de funcionamientos circulares de satisfacción e insatisfacción sensoriales, de violencia y caricias, carentes de profundidad psíquica.

\section{Maltrato y supuestos básicos}

La observación sistemática realizada a partir del registro de los procesos psicoterapéuticos nos permitió establecer diferentes formas de relaciones entre las mujeres maltratadas y sus parejas. Encontramos mujeres que se sometían a sus maridos de manera incondicional, y se quedaban ligadas a ellos por muchos años, a pesar del maltrato constante al que eran sometidas; observamos mujeres atadas a sus esposos en medio de ataques mutuos de gran violencia y destructividad que las ponía al borde de la muerte; también encontramos mujeres que huían por la gravedad del maltrato que caía sobre ellas y sus hijos, pero que temerosas frente a que la vida de sus hombres pudiera estar en peligro, volvían a vivir con los maltratadores. Hubo también algunas mujeres, las menos, que podían alejarse del maltrato, porque tenían las capacidades mentales para hacerlo; o porque movidas por sus propios deseos inaplazables, se vinculaban a otros hombres o regresaban a las familias paternas para recuperar una libertad añorada; o porque el ataque insoportable a uno de los hijos las forzaban a alejarse. Sin embargo, a pesar de estas variaciones encontradas en el material de todas ellas, fue evidente un oscilar entre los supuestos básicos de dependencia, lucha y fuga y apareamiento descritos por Bion (1961/2006), con momentos de supuestos básicos de patraña y engaño, jolgorio y convite, aislamiento y congoja.

Prácticamente, en todas ellas la relación se iniciaba bajo el supuesto básico de patraña y engaño en medio de la seducción y la aparición de una relación idealizada con el "hombre amado", considerado co- 
mo alguien excepcional y novedoso en sus vidas. Al entrar en la relación, la mujer delegaba su cuidado y el de los hijos, producto de uniones anteriores, en el marido. Todas ellas en aquel primer momento entraban en el supuesto básico de dependencia donde aparecía un estado de "devoción y adhesión", pero también de "reverente temor" que las llevaba rápidamente a temer el alejamiento del ser amado. "Lo que dice mi marido bien dicho está" (parafraseando el cuento iBien hecho, esposo mío! [Andersen, 1985/1992]) Parecía ser el eslogan que regía esos primeros momentos de la relación. El marido era visto por la mujer como aquel a quien se le podía pedir ayuda y todo lo resolvía; alabado con frecuencia, el hombre se crecía en poder y comenzaba a ver la debilidad de su esposa. Cargado de frustraciones, de celos o de deseos sexuales inaplazables, comenzaba entonces la fase del dominio pleno, donde aparecían los ataques violentos y crueles frente a cualquier inconveniente que limitara sus deseos o necesidades. Se iniciaban entonces los gritos, los insultos, los golpes, las relaciones sexuales forzadas. El sujeto agresor ejercía sobre la mujer toda su violencia y ella solamente trataba de esconderse o huir porque sabía que si lo enfrentaba, la situación se complicaba y podía llegar a límites cada vez más violentos y más cercanos a la muerte. La mujer, poco a poco, frente a los eventos violentos repetidos, acababa por no poder defenderse y, en medio del terror, renunciaba a la expresión de sus deseos y al ejercicio de sus propias capacidades. En ese momento dejaba de existir psíquicamente. Otras veces los dos caían en la lucha violenta y deshumanizada en las que con frecuencia quedaban heridos.

Bajo la condición de violencia repetida, el marido o compañero entraba en una posición de omnipotencia y omnisciencia extremas, mientras que la mujer caía en un estado de frustración e inadecuación constante y progresiva. El hombre solía caer también en estados de impotencia, temor e inseguridad, que resolvía con una agudización de la situación de destructividad y con eventos de infidelidad que le demostraban a él y a los demás que seguía siendo el hombre potente y poderoso que siempre había sido. Otras veces, los dos reaccionaban de manera violenta, uno contra el otro, e intervenían otros miembros de la familia que se aliaban con una de las partes. El supuesto de lucha y fuga era lo que primaba entonces entre la pareja. Allí se hacían presentes el odio, la destrucción y la desesperación, que finalmente llevaba a la huida de la mujer y sus hijos o al hombre amenazado que quería conservar su vida.

Pasada la tormenta, y habiendo regresado las inquietudes y necesidades sexuales, llegaba el momento del arrepentimiento, del perdón, surgía la fantasía de un futuro mejor, cargado de promesas. El pasado tendía a negarse y el evento violento, recientemente vivido, perdía importancia y surgía la esperanza. Entraban entonces en el supuesto básico de apareamiento. Las dificultades presentes las enfrentaban con imágenes idealizadas de mejoría futura, "una nueva situación" estaba por llegar. Predominaba la esperanza de la reconstrucción de la pareja con la llegada del "nuevo ser" que lo arreglaría todo, del nuevo hijo que mejoraría la relación. Regresaba el marido que expresaba amor con su presencia y con los regalos que traía y así volvía a instaurarse el supuesto básico de dependencia. La pareja pasaba a tener breves períodos de "buen funcionamiento". En medio de relaciones benévolas y atmósferas de paz y tranquilidad relativas, un problema cualquiera proveniente de los celos o de la sensación de abandono por infidelidad, traían de nuevo la tormenta emocional y regresaban la ansiedad, el temor, el odio, presentes en el supuesto básico de lucha y fuga. A manera de un nuevo castigo tántrico (Bauman, 2006), la situación oscilante entre los supuestos básicos se repetía sin mayores variaciones y sin lograr encontrar una salida definitiva al conflicto. Era claro, al oír las narraciones de las mujeres, que para vivir así no era necesario, como decía Bion (1961/2006), ni "entrenamiento", ni "experiencia", ni "madurez mental", ni "actividad intelectual", simplemente la aparición de la pareja de un estado emocional de peligro o ansiedad, abrían paso al siguiente supuesto básico.

El material recogido en el refugio nos mostró la presencia en las parejas maltratadas y maltratadoras, donde tres nuevos supuestos básicos se habían descubierto en los niños callejeros. El primero era el de "patraña y engaño" usados como ventaja en el 
ataque de intensión dominadora o durante la lucha a muerte entre ellos o como defensa en el momento de la huida para proteger la vida; el segundo era el de "jolgorio y convite" que invadía la pareja en el momento de la reconciliación, momento en el que el peligro de un nuevo evento de maltrato quedaba negado y la manía triunfal se hacía sentir; el tercero era el de "congoja y aislamiento" en el que se sumían los dos cuando sentían que habían perdido el intento de recuperación y entraban de nuevo en la destructividad. Se unían en el caso del maltrato la dependencia renovada con jolgorio y convite, lucha y fuga con patraña y engaño y el apareamiento fracasado con congoja y aislamiento.

Esa oscilación constante entre los supuestos básicos se encontró prácticamente en todas las descripciones que las mujeres hicieron sobre el funcionar de ellas y de sus compañeros a lo largo de los años. En medio de ataques renovados, bajo condiciones de violencia extrema, se pasaba a los encuentros en el terreno judicial, con intención de venganza y búsqueda de castigo ejemplar para el agresor, con momentos de jolgorio por haber logrado el castigo del hombre abusador o maltratador. Sentimientos entrecruzados con momentos de congoja por contactar de nuevo un sentimiento de dolor frente a la debilidad que aparecía en el marido agresor, hoy cercano a la cárcel, y una vivencia de aislamiento y soledad cuando pensaban que el hombre desaparecería para siempre. Otras veces, la aparición de un sentimiento de esperanza de futuro frente a las mutuas promesas, o el surgimiento de un nuevo hombre abría el espacio para el jolgorio y al convite frente al nuevo bienestar que estaba por llegar.

Estas parejas maltratadas y maltratadoras parecían originarse y estar envueltas en una atmósfera de atracción sexual intensa, de urgencias sexuales inaplazables, de estados de celos delirantes, bajo la presencia de rivales reales o creados de manera delirante, a los que había que eliminar, en medio de urgencias de apresar al ser amado y someterlo para no perderlo. Esa confusión teñía la imagen de un aquelarre de amor en guerra y persecución apocalíptica, que despertaba promesas mesiánicas de amor eterno. La confusión y las escisiones extremas son la tonalidad adicional de estos movimientos de supuestos básicos. Allí, la dimensión temporal se pierde en medio de la negación de lo malo o la añoranza de lo bueno, donde todo alejamiento es vivido como amenaza de pérdida eterna y solo la cercanía asegura el regreso de lo bueno, porque ya no existe en la mente lo malo que acaba de suceder.

\section{Maltrato, primacía del ello, deshumanización y pérdida del psiquismo}

Las narraciones de Turnbull (1987), en su libro The Mountain People, donde reunió sus hallazgos sobre la tribu de los Ik, nos permitió contactar seres deshumanizados que bajo una vida de escasez y hambruna se habían convertido en personajes carentes de compasión, desconfiados, con expresiones de crueldad y burla frente a las dificultades de los otros, en competencia con los más cercanos, luchando por el bocado que les permitiera mantenerse vivos en un medio ambiente hostil. En esta tribu se producía un aislamiento de las familias y una desarticulación de las relaciones entre marido, mujer e hijos, cada uno de ellos preocupado por su propia supervivencia. Turnbull, en su libro, llamaba la atención sobre la perturbación en el funcionamiento psíquico y social cuando se vive en organizaciones sociales en descomposición y bajo sistemas de valores deteriorados.

La mayoría de las mujeres con quienes trabajamos se encontraban bajo un ambiente análogo de deshumanización, donde primaba la crueldad, la burla, el desinterés y la familia no era una unidad fundamental para la vida social: era solo una herramienta para la supervivencia individual. El ambiente familiar estaba lleno de amenazas de muerte, golpes, humillaciones y desprecio entre la pareja. Carentes de recursos económicos propios y sin contar con el apoyo familiar necesario para hacer una vida independiente, quedaban condenadas al maltrato.

El terror y la desconfianza se instauran en la mente de estas mujeres. En el material clínico, pudo observarse la desconfianza por parte del compañero hacia la mujer maltratada. Desconfianza sobre la paternidad, sobre lo que hacen y dicen 
cuando no pueden vigilar de cerca su comportamiento. Desconfianza que se va convirtiendo en un estado mental paranoico, circundado de nuevos hombres alrededor de la mujer. También aparece la desconfianza y el terror hacia otros miembros de la familia, que se convierten en enemigos cuando tratan de sacarlas del maltrato o cuando intentan devolverlas al lugar aterrador de donde salieron.

El maltrato es una experiencia en sí misma deshumanizante, donde la preocupación por el otro parece no estar presente. Las madres suelen cerrar los ojos ante los abusos que el compañero padre hace a sus hijas o a sus hijos, pero otras veces surge el deseo de protegerlos cuando sus vidas o integridad están en peligro. El vínculo que se crea entre las parejas está teñido de seducción y terror, oscilan entre la barra de chocolate o el arma cortopunzante. Se mueven entre estrategias para complacer o para protegerse en el momento, como si en ellas no hubiera una dimensión temporal ni espacial amplia, ni un yo con capacidad plena de conciencia. Lo que se observa en ellas es un ello-yo reactivo que responde a la agresión con agresión, o que huye temporalmente, o que simplemente se queda quieto e impotente, esperando que la agresión termine y se inicien de nuevo el bienestar. Son mujeres carentes de funciones claras de percepción, atención, memoria, juicio, reflexión, comprensión e imaginación, como si vivieran solo en el mundo sensorial inmediato y concreto (Bion, 1992/1994; Meltzer, 1975/1979).

"Mientras tenga techo, comida y hombre, el resto no importa", parecieran decir algunas mujeres maltratadas; "Mientras la mujer sea mi propiedad, y yo pueda hacer con ella lo que yo quiero, entre menos me proteste y más me obedezca, más me quedo junto a ella o la fuerzo a que se quede junto a mí", parecieran decir los hombres. "Lo importante es mi satisfacción y la confirmación de mi ser viril", parece decir el hombre maltratador de la pareja sumida en el maltrato (Green, 1992). En su funcionar, el que predomina es el ello. He aquí el meollo de la deshumanización que produce la vida de supervivencia propia de muchas de las parejas maltratantes.

\section{Maltrato, unidimensionalidad y bidimensionalidad}

En su libro Exploración del autismo: un estudio psicoanalítico, Meltzer (1975/1984) formula su teoría sobre la dimensionalidad del espacio psíquico. Unidimensional, bidimensional, tridimensional y tetradimensional son concebidas como espacios donde las cualidades del self y de los objetos, las formas de relacionarse y las visiones del mundo varían entre sí.

Meltzer define la unidimensionalidad en términos de puntos que se mueven accidentalmente en un espacio amorfo, en "un 'mundo con un centro fijo en el self y con un sistema de rayos en dirección y a distancia de los objetos, concebidos como potencialmente atractivos o repelentes" (Meltzer, 1975/1984, p. 98), allí la gratificación se convierte en fusión accidental, sin que haya mente, ni memoria, ni pensamiento. Es el mundo de la acción-reacción por atracción y repulsión. El más primitivo y menos psíquico de los mundos.

La bidimensionalidad implica concepciones del self y de los objetos ligadas fundamentalmente a la sensualidad, al encuentro de superficies planas sensibles, capaces de percibir y apreciar "las cualidades de la superficie de los objetos” (Meltzer, 1975/1984, p. 199). Carentes de imaginación, no pueden "construir en su pensamiento objetos o hechos distintos de aquellos experimentados de manera concreta" y la memoria, el deseo y la previsión están disminuidos. La introyección en este mundo no es posible, lo único que pueda darse es identificación por adhesión. Hasta este momento el psiquismo no se ha instaurado ni desarrollado, solo existen las pulsiones y la sensibilidad perceptual, pero no hay mundo interno, ni realidad psíquica. Se planteó que los objetos invasores o abandónicos, carentes de capacidad de contención, como objetos concretos de la realidad externa suelen llevar a procesos de desmentalización transitoria o de conversión en el cuerpo que refleja el control sustituto del objeto. Todo esto se produce en la realidad externa, no en la realidad interna.

Para Bion (1962/2008, 1964/1980), el objeto continente, capaz de cumplir con una función de contención, rêverie y pensamiento, permite al bebé 
desarrollar la atención y la conciencia, la imaginación y el pensamiento, como expresión de la existencia de la realidad psíquica.

Para Meltzer (1975/1984), la tridimensionalidad representa un cambio en el espacio que conlleva modificaciones en la concepción de los objetos y del self, que se han convertido ahora en volúmenes con espacio interior, con paredes resistentes y puertas de entrada y salida. La continencia y la resistencia a la penetración agresiva son las que crean el mundo interior, lugar donde es posible entrar y salir, depositar o quitar elementos entonces disponibles. En la tridimensionalidad se da la primacía de la omnipotencia, el control al objeto y la identificación proyectiva como forma de acceder a este, lo cual conduce a la confusión self-objeto y la reversibilidad de la dirección oscilatoria del tiempo (Meltzer, 1975/1984). La tetradimensionalidad es el punto final de la evolución de las dimensiones del espacio psíquico. Este espacio solo aparece cuando caen el narcisismo, la omnipotencia y el control al objeto y surge la identificación introyectiva como una forma de interiorizar las cualidades valiosas de los objetos cercanos o lejanos (Meltzer, 1975/1984). Los dos estados anteriores no se encontraron en las mujeres maltratadas. El abandono y el maltrato temprano padecido por la mayoría de las mujeres maltratadas, en familias donde los padres son invasores, abandónicos, irritados y violentos, carentes de "contención, rêverie y pensamiento", que no permiten crear el espacio interior, las dejan convertidas en trozos aislados de experiencias no conectadas en el tiempo ni en el espacio o en superficies planas donde cualquier experiencia que tenga lugar se resbala sin dejar ningún rastro de existencia o queda convertida en narraciones planas que se repiten una y otra vez, sin que haya en ellas resonancia afectiva acorde con la gravedad de lo vivido.

\section{Reflexiones finales}

Cuando estábamos por terminar este trabajo nos encontramos con algunas reflexiones de Bion y de Meltzer, utilizadas en el capítulo "El terreno de la inexistencia" ("terror a la turbulencia" de su libro Clínica psicoanalítica (en proceso de publicación).
Estas respaldaban de manera adicional las ideas que habíamos expuesto en el artículo respecto al estado no mental, a la estrechez o la aniquilación del psiquismo en quienes viven y están sometidos al maltrato, que queremos compartir en las reflexiones finales.

En su libro Cogitaciones planteaba Bion (1992/1996) que algunas intolerancias mentales, entre ellas la intolerancia a la capacidad negativa, a la incertidumbre, a lo desconocido, parecían estar relacionadas con el uso de sustitutos que llenan inadecuadamente lo no tolerado. Estos aparecen cuando la intolerancia lleva a negar el espacio vacío, que se llena de ideas o sentimientos que no permiten contactar la experiencia real de lo no sabido o no vivido y generan perturbaciones en el desarrollo psíquico. Para Bion, la intolerancia a la frustración es la base la "sustitución prematura y precaria de la inmadurez por la madurez precoz, la confusión por el orden, el desamparo por el poder y la impotencia por la omnipotencia" (pp. 323-324). Se presentan intolerancias a la frustración, lo desconocido, lo incierto, la inmadurez, la confusión, el desamparo y la impotencia, entre otras. Añade Bion que el orgullo desmesurado (producto de la intolerancia a la impotencia) lleva a usar el pensamiento como sustituto de la acción y a esta como sustituto del pensamiento, y que la incapacidad para tolerar el espacio vacío (capacidad negativa) limita la extensión del espacio accesible, con lo cual quiere decir que la profundidad psíquica hacia adentro y hacia afuera se aplana. Amplía, además, que la satisfacción lograda con sustitutos destruye la capacidad de diferenciar "lo verdadero de lo falso, lo importante de lo periférico", situación que "se expresa en la omnipotencia del impotente". Para Bion el vacío que no se tolera se convierte en envidia, odio, destrucción y paranoia, lo cual estimula la avidez, el uso de sustitutos, la madurez precoz, la memoria y el deseo (Bion, 1992/1996, pp. 323-324).

En Atención e interpretación, Bion (1970/1974) vincula la incapacidad "excesiva" para tolerar la frustración a la destrucción de la preconcepción, instrumento que permite tomar conciencia de las realizaciones y construir el concepto. En su defecto, se utiliza el dominio de la alucinación que nace de 
la unión entre la intolerancia a la frustración y el deseo. Surge entonces el temor al dolor que lleva a sentir el dolor, pero no el sufrimiento del dolor propio o ajeno. Se llega a sentir el dolor que causa la falta del cumplimiento del deseo como "no cosa" y la emoción es vivida como indiferenciada de la "no cosa". La "no emoción remplaza la emoción" y "toda emoción sentida es una "no emoción". Algo similar sucede con el tiempo, cuando el pasado o el futuro sustituyen el vacío donde el presente solía estar. Finalmente, concluye, de manera general, que el "lugar donde el tiempo o un sentimiento o una nada de cualquier tipo estaba" puede ser aniquilado de manera similar (Bion 1970/1974, pp. 23-24). Con estas ideas en mente, está abierto el espacio para la idea del aniquilamiento de la mente, de la estrechez o desaparición del psiquismo, donde una vida grupal acaba con la vida de contacto y vínculos sociales propios.

Refiriéndose al terreno de lo individual, Bion (1970/1974) afirma que las exigencias de la acción y la gratificación sensorial chocan con la exigencia de la "actividad" mental. La intolerancia a la frustración lleva a una sustitución del pensamiento por la acción, de la misma manera que la intolerancia a la turbulencia emocional, es decir, a la presencia de emociones contradictorias y complejas en la mente, lleva al funcionamiento mental de categoría 2 de la tabla o al uso de sustitutos que impiden el desarrollo mental y crean una confusión entre lo verdadero y lo falso, entre lo central y lo periférico, entre el continente y el contenido, entre la integración y la desintegración, que llevan al rompimiento de la preconcepción y del aparato para pensar en un proceso constante de destrucción del movimiento en doble dirección entre los polos opuestos para evitar la frustración, apelmazándolos o eliminado uno de los dos.

La vida miserable de las mujeres maltratadas puede mantenerse, porque la ausencia de padres protectores y cuidadosos, y la presencia del abandono o del maltrato y del abuso desde muy temprano les impidieron tolerar la frustración indispensable para desarrollar la vida psíquica, las dejaron funcionado siempre en la concreción de la realidad externa, llena de confusiones que impiden las di- ferenciaciones mentales básicas que hacen posible alejarse del maltrato.

Meltzer en el capítulo "Las sombras en la caverna y la escritura en la pared" de su libro Aprehensión de la belleza (1988/1991), establece una interesante oposición entre tres personajes que reflejan formas diferentes de concebir y enfrentar el mundo:

Ahab que encarna las fuerzas del menos L, H, K (Love, Hate, Knowledge), el tirano, el fariseo, el que cree en castigar con la lanza y recompensar con la guinea de oro (...) no tiene emociones, sino que es consumido por la obsesión y un delirio de prerrogativas cuasi-divinas (...) consumido (...) pues está destruyendo su propia capacidad de sentir y de pensar y Starbuck como el artista-científico, que ve que la belleza del exterior oculta un misterio interno que incluye al tiburón dentudo y los modales de secuestro caníbal como integrantes de la verdad, la belleza y la bondad del todo. Stubb es el sensualista que vive en la superficie del mundo y ha olvidado el vientre de su madre. Su jovialidad infinita y bidimensional tiene un carácter resistente que lo ata a la mentalidad tribal de los tres arponeros. (Meltzer \& Harris Williams, 1988/1991, p. 203)

Las mujeres y los hombres maltratadores funcionan más como Ahab en el terreno de la unidimensionalidad, de la acción de un ello-yo irrefrenable, carente de verdaderas emociones y pensamiento, o como Stubb en el campo "sensorial jovial" de la bidimensionalidad que los lleva en línea recta hacia los supuestos básicos. Sin diferenciaciones adecuadas y carentes de mente, pueden vivir vidas miserables sin contactarlas realmente.

Finalmente, nos encontramos con las reflexiones de Green en relación con la diferenciación entre bueno y malo, bien y mal en su libro La nueva clínica psicoanalítica y la teoría de Freud (2001), donde, después de hacer un recorrido por el pensamiento de Freud y Klein, afirma que "la articulación entre lo malo en el sentido de perseguidor, el que me quiere hacer mal y lo malo en el sentido del pecador, aquel en mí que quiere el mal del otro" permiten diferenciar la cualidad y la relación con el objeto, pero también darle a la perversión un componente 
de odio y de daño donde se manifiesta la pulsión de muerte, donde la sexualidad va unida al mal.

La relación entre destructividad y mal lo lleva a hablar de una desinvestidura brutal que deja a los otros convertidos en una nada, cuando los vínculos de amor y odio desparecen. La existencia de una destructividad que reclama "venganza inextinguible, donde aún está presente la libido erótica, por la pasión que expresa”, en su dimensión más extrema lleva al "anhelo de aumentar el padecimiento" del otro, o aún peor a ignorarlo. Todo esta situación se opone a la experiencia del bien, que se "funda en la simpatía" hacia el "padecimiento del otro y que "impulsa a aliviar al que pena" (p. 195). Estas reflexiones llevan a Green a definir al malo como aquel que "ama el mal" donde lo que está presente es la "destrucción pura e integral" que pierde el sentido de la existencia humana que da "la dicotomía bien/mal fundadora del orden (...) de las significaciones de la vida social" (p. 202). Se trata en realidad del surgimiento de un acto narcisista que "procura la aniquilación de lo que no es él, o el sometimiento total, definitivo, absoluto de lo que se opone" (p. 203). Podría pensarse que en esta relación de maltrato y violencia, existe una mezcla indiferenciada entre excitación-odio-satisfacción, que adquiere cualidad de droga de adicción que no puede suspenderse.

Ese narcisismo va creando grupos humanos asediados por la violencia y por las fuerzas malévolas que llevan a la "desobjetalízación como consecuencia de la pulsión de muerte", que a su vez conduce a "la indiferencia del verdugo ante el rostro de su semejante considerado como extraño absoluto y aun extraño a la humanidad" (p. 207). En términos de Green, lo que se persigue es "el poder que se pueda ejercer para imponer su voluntad a los objetos de sus apetitos", no el "deseo" que sería en sí un término "demasiado civilizado". Allí solo están presentes el ello y las pulsiones destructivas, "un mal sin por qué, cuyo rasgo característico es la "desligacion integral", el "no-sentido", la "fuerza pura" (p. 210). Todas estas características que Green va estableciendo sobre el mal, sobre la desligazón brutal o integral son las que encontramos en los miembros de las parejas maltratadoras. Vistas en su realidad social solo reflejan la sociedad violenta y miserable en la que viven.

Para terminar quisiéramos afirmar que el psiquismo, bajo condición de maltrato temprano o prolongado en el tiempo, puede verse invadido desde adentro por demandas corporales y/o urgencias pulsionales, al mismo tiempo que por distorsiones sociales y culturales externas que impregnan el funcionamiento violento de una sociedad inhumana. La parte infantil de la mente, invadida por estas urgencias de satisfacción corporal, domina la escena e intenta con todas sus fuerzas y defensas omnipotentes, oponerse, luchar, destruir los aspectos del sî mismo interiorizados protectores (objetos buenos internos), que pueden intentar limitar sus exigencias narcisistas. De esta manera, se configura una alianza entre el ello-yo, voraz, unido a las fuerzas orgánicas por una parte y las culturales invasoras, por otra, aniquila lo poco que pueda quedar de una orientación social humanitaria dirigida hacia el cuidado y la protección del otro y del sí mismo.

Este estado de cosas, nos deja ver el impacto que la experiencia de la violencia tiene sobre el psiquismo de las personas, sobre la repetición de este tipo de funcionamiento entre los miembros de las familias maltratantes que, a su vez, reflejan un funcionamiento grupal donde el sujeto como tal no es considerado. Lo que se pone en escena más allá de las precarias condiciones de vida para la mayoría de los ciudadanos en un país lleno de inequidades de toda clase, es la miseria psíquica y relacional, en la cual el sujeto humano y los valores que tradicionalmente consideramos adecuados ya no cuentan. El valor se ubica en los números, las cifras, la aritmética, pero no cuentan las condiciones que pueden o podrían hacer de una sociedad un lugar habitado por personas con sueños, afectos, relaciones apasionadas, plenas de sentimiento hacia otros y generadoras de proyectos comunes. El gran reto que tienen las Ciencias Humanas frente a este panorama es volver a centrar la atención en aquello que nos hace humanos. Lograr dirigir las acciones y favorecer los procesos educativos, sociales, de salud, de cultura que permitan a las nuevas generaciones recuperar las nociones de cuidado y protección inherentes al desarrollo psíquico y social 
(Torres, 2005, 2011). Donde, como afirma Green, "el principio de realidad" lleve al "Complejo de Edipo como ordenador simbólico del orden humano" y de esta forma salir de la condición de supervivencia salvaje, del desorden que no reconoce diferencias ni de edad ni de generación, que produce confusiones entre el bien y el mal, la vida y la muerte, el niño y el adulto, el hombre y la mujer, los padres y los hijos, y promiscuidades generadoras de nuevas y dramáticas confusiones.

\section{Referencias}

Amaya, M. (2012). Exploración de la mente en tres mujeres maltratadas. Trabajo de grado para optar por el título de Magíster en Psicología Clínica, Pontificia Universidad Javeriana, Bogotá, Colombia.

Anderson, H. (1992). Cuentos clásicos (Vol. 1). México: Fernández Editores. (Trabajo original publicado en 1935)

Bauman, Z. (2006). Comunidad: en busca de seguridad en un mundo hostil. Madrid: Siglo XXI.

Bion, W. (1974). Atención e interpretación. Buenos Aires: Paidós.

Bion, W. (1980). Elementos de psicoanálisis. Buenos Aires: Paidós.

Bion, W. (1996a). Cogitaciones. Valencia: Promolibro.

Bion, W. (1996b). Volviendo a pensar. Buenos Aires: Hormé-Paidós.

Bion, W. (2001). Transformaciones. Valencia: Promolibro.

Bion, W. (2006). Experiencias en grupos. Buenos Aires: Paidós.

Bion, W. (2008). Aprendiendo de la experiencia. Buenos Aires: Paidós.

Caro, J. (2012). El maltrato en la pareja, trampa y prisión psíquica. Trabajo de grado para optar por el título de Magíster en Psicología Clínica, Pontificia Universidad Javeriana, Bogotá, Colombia.

Freud, S. (1981a). El Yo y el Ello. En S. Freud, Obras Completas. Madrid: Biblioteca Nueva.

Freud, S. (1981b). Escisión del yo en el proceso de defensa. En S. Freud, Obras Completas. Madrid: Biblioteca Nueva.

Freud, S. (1981c). El compendio de psicoanálisis. En S. Freud, Obras Competas. Madrid: Biblioteca Nueva.
Gil, B. (2010). Las niñas y las víctimas de incesto tienen desagada la matriz cuerpo-mente, una mirada femenina a la medusa. Trabajo de grado para optar por el título de Magister en Psicología Clínica, Pontificia Universidad Javeriana, Bogotá, Colombia.

Green, A. (1992). El complejo de castración. Buenos Aires: Amorrortu.

Green, A. (2001). La nueva clínica psicoanalítica y la teoría de Freud. Buenos Aires: Amorrotu.

Klein, M. (2001a). Notas sobre algunos mecanismos esquizoides. En M. Klein, Obras Completas. Buenos Aires: Paidós.

Klein, M. (2001b) Nuestro mundo adulto y sus raíces en la infancia. En M. Klein, Obras Completas. Buenos Aires: Paidós.

Klein, M. (2001c). Relato del Psicoanálisis de un niño. En M. Klein, Obras Completas. Buenos Aires: Paidós.

Meltzer, D. (1984). Exploración del autismo: un estudio psicoanalítico. Buenos Aires: Paidós. (Trabajo original publicado en 1975)

Meltzer, D., \& Harris Williams, M. (1991). La aprehensión de la belleza: el papel del conflicto estético en el desarrollo, la violencia y el arte. Buenos Aires: Spatia. (Trabajo original publicado en 1988)

Muñoz, C. (2011). Reflexiones psicoanalíticas. Bogotá: Javegraf.

Muñoz, C. (2014). Clínica psicoanalítica. Doce estudios de caso y algunas notas de técnica. Bogotá: Javegraf.

Navarrete Mejia, N. (2002). Perspectiva de la investigación social de segundo orden. Cinta de Moebio. Revista de Epistemología de Ciencias Sociales,14, 200-225.

Olarte, T. (2012). Exploración del funcionamiento psíquico de dos dos adolescentes y una niña que han vivido experiencias de violencia intrafamiliar. Trabajo de grado para optar por el título de Magister en Psicología Clínica, Universidad Javeriana, Bogotá, Colombia.

Rincón, P. (2010). La terrible condena de la mujer maltratada. Trabajo de grado para optar por el título de Magister en Psicología Clínica, Universidad Javeriana, Bogotá, Colombia.

Sanguino, B. (2011). Impacto de las diferentes formas de maltratao en el desarrollo del niño víctima de la 
violencia intrafamiliar. Trabajo de grado para optar por el título de Maestría en Psicología Clínica, Universidad Javeriana, Bogotá, Colombia.

Torres, N. (2005). El psicoanálisis y su acercamiento a otros contextos: una propuesta de categorias de encuentro. Universitas Psychologica, 4(1), 77-83.

Torres, N. (2011). Sobre la muerte en vida o la degradación psíquica. En La Muerte: siete versiones, una realidad (pp. 137-157). Bogotá: Javegraf.
Turnbull, C. (1987). The mountain people. New York: Simon \& Schuster, Inc.

Zacipa, J. (2010). Estructura psíquica del agresor sexual, una mirada desde el psicoanálisis. Trabajo de grado para optar por el título de Magister en Psicología Clínica, Universidad Javeriana, Bogotá, Colombia. 